\title{
ACRL in Chicago ACRL programs at the ALA Annual Conference
}

A

LA's 136th Annual Conference was held June 22-27, 2017, in Chicago. More than 22,700 librarians, library support staff, exhibitors, writers, educators, publishers, and special guests attended the conference. $E d$. note: Thanks to the ACRL members who summarized programs to make this report possible.

\section{Fostering agility}

Bernard Banks challenged the audience to think differently about how to create change in our libraries in the joint Presidents' Program of ACRL and the Public Library Association.

Warning that change is more than creating a strategic plan, he affirmed

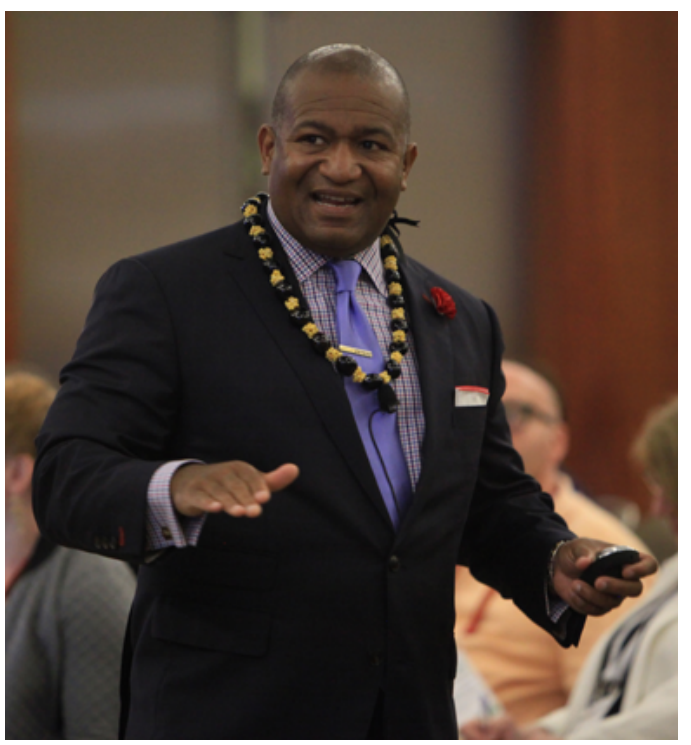

Bernard Banks at the joint Presidents'Program of ACRL and the Public Library Association. fail-because we often learn better through those failures.

Banks equated the process of encouraging failure and learning from it to the correct level of "tears" in a muscle while strength-building. If you do not exercise a muscle enough, it doesn't change. If you exercise too much, you damage the muscle instead. Are we enabling our staff to make smart tears? Without taking risks and failing, we stagnate. Fostering agility requires us to seek feedback, update our knowledge and expertise, take risks or allow others to stretch, discuss our mistakes with others, and, finally, collaborate across diverse backservation that "culture eats strategy for breakfast." He described ways an organization's culture can negatively impact change efforts. To create an agile, change-ready organization, we need to alter that underlying culture by thinking carefully about how we reward staff, what we measure, and what we encourage staff to attempt. Leaders need to create opportunities for staff to risk and grounds and perspectives so that we are continuously challenged. Three of his final questions were: To what extent does your culture value learning? What experiences are you creating, and how are you measuring them? What risks are you underwriting, and why? He recommended Assessing culture, by Edgar Schein (1992), and Triggers: Creating behavior that lasts-Becoming the person 
you want to be, by Marshall Goldsmith and Mark Reiter (2015) as additional reading.-2017 President's Program Planning Committee

\section{Visibility and engagement}

The Distance Learning Section sponsored "Visibility and Engagement: Design, Develop, or Refresh Your Online Instruction," a panel session moderated by Molly Mansfield (Dominican University) that presented four librarians' successes and learning opportunities in creating high-impact online instruction.

Kelly Diamond (West Virginia University) shared her early-to-midcareer experiences from an "accidental instructional designer" to a librarian holding a graduate certificate in instructional design. She highlighted key points learned, including this valuable technology insight: "Technology supports online instruction; it is not the focal point . . clear design and pedagogical principles are the most important element."

Kristin Woodward (University of Wisconsin-Milwaukee [UWM]) detailed several principles of UWM Libraries' information literacy design philosophy, including parity of online and face-to-face instruction, refreshing one-third of content annually, and partnering with faculty to create authentic learning activities. On keeping videos updated with web and database changes, she recommended, "Make sure every video has a concept at its heart. [This allows the students] to still learn the concept, even if the step-by-step has changed."

Claudia McGivney (Stony Brook University) has been using reflective exercises in online information literacy instruction for several years. She discussed the challenges and successes, including moving students from summarizing to critically engaging, the adaptability of the exercises, and instructor insight into what students are struggling with. "Journaling can help students become more critically literate," McGivney reported.

Susan Wengler (Queensborough Community College-CUNY) detailed the solutions her team applied to improve an online information literacy course, including encouraging students to share anxieties about online learning, offering extra credit drop-in help sessions, assigning practice research topics, and mentoring students in the location and evaluation of sources. Wengler stated that "Online course shells can and should improve over time with reflection and revision."

Recurring themes from the panel included reflection, revision, assessment, and redesign. -Michael English, George Mason University, menglis7@gmu.edu

\section{Impactful partnerships}

The Education and Behavior Sciences Section and the University Libraries Section cosponsored "Impactful Partnerships: Navigating the Evolving Scholarly Communication Landscape With Faculty." Members of the panel were Karen E. Gutzman (impact and evaluation librarian at Northwestern University, Feinberg School of Medicine); Rachel Borchardt (Science librarian at American University); and Nicky Agate (head of Digital Initiatives and manager of MLA Commons, the CORE repository, and Humanities Commons at the Modern Language Association [MLA]). They focused on their experiences with tracking scholarly output and resulting changes and adaptations to their current practices. All three stressed that this field is constantly changing for librarianship, a fact that practitioners, faculty researchers, and administrators should be aware of. The growing importance of altmetrics was also discussed, with each presenter explaining the areas of altmetrics they track and the burgeoning importance of a social media presence.

Gutzman stressed librarians' leadership role in explaining to researchers the importance of establishing an online identity and strongly urged the use of open access for all scholarship. When faculty work is openly available online, it's more likely to be downloaded, and more exposure is always better.

Borchardt discussed the need for librarians to contact early-career researchers and 
recommended an aggressive policy of outreach to all incoming faculty. She described her Lunch and Learn events that feature a Metrics Game and told the audience to never underestimate the power of good food to promote library services.

Agate eloquently informed the audience about the newest efforts of MLA to help its members establish their scholarly identity. She emphasized exposure and encouraged faculty to put their work online and to actively engage in self-promotion. She also asked librarians and faculty to think deeply about why faculty are being measured

Kristin Briney (data services librarian at Sara Mannheimer (data management librarian at Montana State University) spoke about libraries' ongoing balancing act between a desire to improve and serve, while maintaining patron privacy and confidentiality. She reminded attendees about our ethical standards for privacy and autonomy, but also noted how much data is already being captured-both within the library and by third-party vendors-and she emphasized the need for institutional responsibility. She noted the need for library privacy guidelines to address our internal practices. and suggested that the focus of scholarly communication should be on measuring what scholars value.-Benita Strnad, University of Alabama, bstrnad@ ua.edu

\section{Collecting library data}

The panel "Collecting

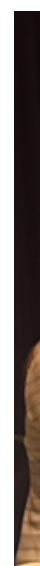

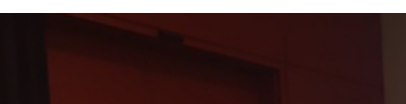
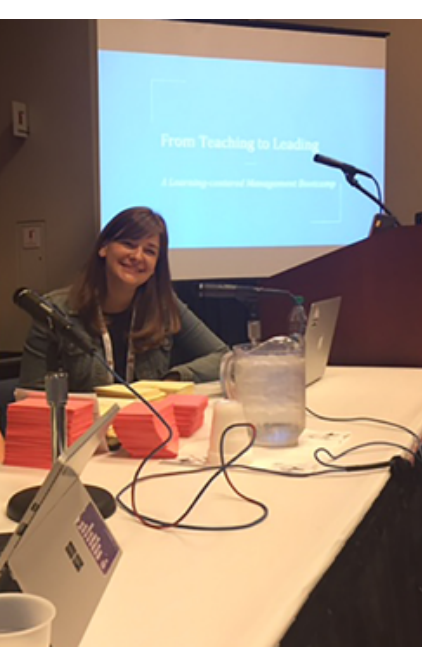

"From teaching to leading" presenters (left to right): Lauren Pressley, Carrie Donovan, and Rebecca K. Miller. the University of WisconsinMilwaukee) a ddressed issues with current library projects that leverage patron-identified data. She pointed out the ways we can draw from research data management best practices, specifically having data management Library Data:

Policies and Data Management Procedures for Improvement" combined a focus on library data capture and analytics with questions and concerns about the ethical and practical issues with that data.

Jenica Rogers described the data-gathering administrative tightrope that she walks as director of libraries at SUNY-Potsdam. While a quick colleague survey showed great interest in determining if use of library services correlated to GPA and an ease in gathering aggregate student search logs, a student survey pointedly showed that less than $10 \%$ were comfortable with any tracking data being attached to demographic information and $0 \%$ wanting their search logs tied to identifying data. and security plans. She encouraged the attendees to ask about data access, responsibility, and retention periods. She also reviewed the challenges with truly performing data de-identification, reminding that this may put marginalized patrons further at risk.

Panel coordinator Abigail Goben (associate professor at the University of IllinoisChicago) led the panel through preplanned questions on addressing these issues when not in a position of power or avoiding an IT data-grab before opening it to the audience for an enthusiastic Q\&A.-Abigail Goben University of Illinois-Chicago, abigailgoben@ gmail.com 


\section{From teaching to leading}

In the ACRL program "From Teaching to Leading: A Learning-centered Management Bootcamp," presenters Rebecca K. Miller (Penn State), Lauren Pressley (University of Washington-Tacoma), and Carrie Donovan (Ferris State University) led participants through guided discussions surrounding the idea that many skills that instruction librarians gain through teaching experiences are transferrable to management and other leadership roles.

Donovan started the workshop by stating that libraries need transformative leaders, and that teaching and learning librarians are particularly well-equipped to fill these roles. She articulated a number of examples of how instruction-related skills and practices transfer into management or leadership skills and practices. Backward design, for example, can translate into setting strong institutional outcomes. Donovan then asked participants to inventory their own skills that could translate into a leadership role. These included emotional intelligence, self-awareness, classroom management, setting expectations, public speaking, flexibility, relationship-building, and assessment.

Miller discussed the way learning theories can provide philosophical or foundational underpinnings for successful library leaders. She spoke about the importance of developing a personal canon of theory that can inform behavior and decision-making, and shared her own, which included Vygotzky's Zone of Proximal Development, Lave and Wenger's Situated Learning Theory, Mezirow's Transformative Learning Theory, and instructional design. She then shared how these theories can transfer into the leadership realm. For example, Transformative Learning Theory can inform processes for helping professionals step into new, evolving roles.

Finally, Pressley encouraged participants to develop an action plan for stepping into leadership roles, including inventorying their skills, personal canon, and learning opportunities. She concluded the session with a call to action, reminding participants that libraries now, more than ever, need learning- and people-centered leaders. Teaching and learning library professionals fit this description and should consider the many ways that their skills, backgrounds, and experiences can prepare them to be transformative leaders.-Rebecca Kate Miller, The Pennsylvania State University, rkm17@psu.edu

\section{Libraries and the military/veteran population}

Librarians and Armed Forces veterans Sarah LeMire, Ingrid Ruffin, and Dawn LaValle presented on how libraries can better serve military veterans in "Libraries and the Military/Veteran Population: Transformative Service Through Cultural Competence." They described the military as an insular, close-knit, and self-sufficient group who may hesitate to request or take advantage of government services to which their service entitles them or to use public services. Some veterans may have disabilities-like traumatic brain injury-may have experienced sexism or assault in the military, or may have been in positions of power in the military yet still face sexism or ageism in the civilian world, complicating their transition to post-military life.

They may also avoid self-identifying as veterans to avoid drawing attention to themselves. Presenters suggested creating spaces where veterans who have been trained to be situationally aware can have a wall behind them, limiting study distractions. Academic librarian Ruffin stressed the importance of providing training to help librarians work effectively with military populations.

Academic librarian LeMire noted that veterans may have educational gaps from their time in the military, and may need support transitioning to civilian life. Having librarians who can connect veterans with organizations that can explain their military benefits, like the GI Bill; make recommendations for doctors, dentists, or other experts; and help veterans translate the skills they learned in 
the military to fit job requirements in civilian positions is vitally important.

State Library Division Director LaValle also suggested librarians coordinate with local veterans organizations, such as the U.S. Department of Veterans Affairs, that provide services and programs. Also, giving veterans opportunities to share their experiences through library exhibits, writing groups, or other activities can help them feel more involved in the community.-Lorelei Rutledge, University of Utah, lorelei.rutledge@utah.edu

\section{Mentoring}

Mentoring continues to play a critical role in professional development for new librarians. The presentation "Mentoring: Blending Old and New," presented by Michelle Carter and Lindsey LeFeber (both from the College of Lake County [CLC]), demonstrated that the tradition has evolved in ways that benefit both the mentor and mentee.

Carter began by clarifying the title of their session, "Old equals experienced; new

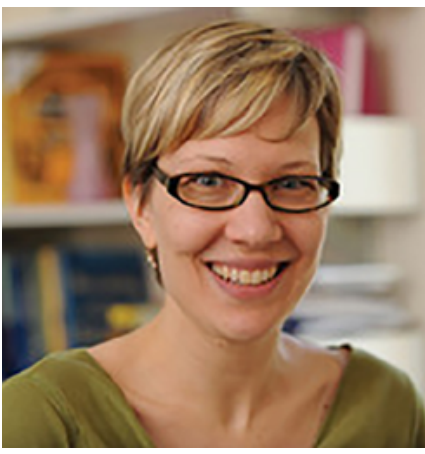

"Reframing the Framework for Social Justice" presenter Laura Saunders.

\section{equals new to the profession.}

Mentoring has little to do with the age of the mentor or mentee." Working together they have learned from each other to find new ways to connect with CLC students.

Carter believes that mentoring is part of our role as professionals: in leadership development, in creating an improved workplace, and to ensure independent growth for both the mentor and mentee.

For LeFeber, a mentor is "someone outside of your immediate circle who has the knowledge, sees your strengths, supports your goals, and pushes you just outside of your comfort zone to help you reach your goals."

Carter, who has more than 30 years of library experience, is able to share institutional knowledge with LeFeber and offers advice on working with instructors at the college. LeFeber has been able to bring a fresh per- spective in student engagement, technology, and social media trends. Together they say that their relationship is best when they both keep an open mind. As Carter stated, "As a mentor, you have to remember not to say, 'But we did that ten years ago!' A new perspective may yield positive results."

Humor also keeps their mentoring relationship positive. "Laughing at myself has gotten me over a lot of hurdles," Carter said. For both parties, Carter feels it is important to "Leave your ego at the door, and don't presume you know everything!"-Donna MacCartney, College of Lake County, dmaccartney@clcillinois.edu

\section{Reframing the Framework for social justice}

In this presentation, Laura Saunders (Simmons College) made a case for integrating a social justice perspective into the ACRL Framework for Information Literacy for Higher Education. ${ }^{1}$ She suggested that the role of higher education could be seen as preparing students to actively participate in a democracy and, as such, students must understand and be able to challenge the inherent power structures within which information is created and disseminated. Saunders proceeded to move frame by frame, offering suggestions for integrating a social justice perspective into each of the six frames, along with occasional examples of activities or assignments related to those perspectives. For example, instruction on Information has Value could address issues of the commodification of information and how the cost of texts and technology impacts access.

Saunders concluded with a proposal for a new frame, Information Social Justice, which could become part of the Framework or adapted by other interested parties. She argued that integrating social justice throughout the Framework presents a risk of having 
that perspective get buried or overlooked, while a separate frame would highlight social justice aspects. The draft frame, ${ }^{2}$ available for comment on Saunders' website, emphasizes students' ability to critically analyze, question, and challenge sources of information and constructions of authority in order to empower them to act for change.

During discussion, participants indicated interest in the topic but also acknowledged the challenges, including limited in-class time and the expectations of faculty about topics and outcomes covered. Participants also acknowledged the pressure on marginalized communities to constantly act as standardbearers despite ongoing discrimination.

\section{Notes}

1. "Framework for Information Literacy for Higher Education," ACRL, last modified January, 11, 2016, www.ala.org/acrl/standards /ilframework.

2. Laura Saunders, "Information Literacy Frameworks and Social Justice," accessed July 27, 2017, http://slis.simmons.edu/blogs /saunders/information-literacy-frameworks -social-justice.-Laura Saunders, Simmons College SLIS, laura.saunders@simmons.edu

\section{Re-skilling librarians for a digital future}

As digital scholarship expands across the disciplines, librarians increasingly encounter questions from users who pursue datadriven research and teach with digital tools. The ACRL-sponsored program "Re-Skilling for a Digital Future: Developing Training and Instruction in Digital Scholarship" featured a panel of three speakers who discussed their experiences in implementing training initiatives for preparing librarians to support digital scholarship.

Nora Dimmock (University of Rochester) presented on the Mellon Foundation-funded Rochester Digital Humanities Institute, and described how they developed a digital humanities training program targeted specifically for mid-career library professionals. She shared engaging anecdotes from their experiences in carrying out the training program, explained the lessons learned from their assessment data, and recounted success stories of librarians developing their own digital scholarship services after the Institute.

Angela Courtney (Indiana UniversityBloomington) then presented on Indiana University Libraries' local training initiative called "Research Now," which was designed to crosstrain public services librarians in areas of digital scholarship when the reference desk was integrated into their Scholars Commons. She described how the two-year crosstraining project involved librarians from departments throughout the library, and how it resulted in librarians becoming engaged in multiple areas and new library initiatives.

Harriett Green (University of Illinois at Urbana-Champaign) spoke about the IMLSfunded project "Digging Deeper, Reaching Further: Libraries Empowering Users to Mine HathiTrust Digital Library Resources." Green described how the project team has developed materials designed to train librarians in text mining, and how their upcoming national series of workshops aim to build a community of practice and enable more librarians to support digital scholarship. An audience of 40 attendees subsequently asked questions about resources for digital scholarship and strategies for building digital scholarship services in their libraries.-Harriett Green, University of Illinois at Urbana-Champaign, green19@illinois.edu

\section{Students lead the library}

This panel discussion, based on the recently published ACRL volume Students Lead the Library: The Importance of Student Contributions to the Academic Library, focused on four student-led initiatives in academic libraries.

Moderator Sara Arnold-Garza (research and instruction librarian at Towson University) introduced theoretical aspects of student-led initiatives, including peer and experiential learning, promoting relationships and interactions, and promoting the role of libraries in student engagement. 
Jamie Kohler (collection management librarian at Westminster College) discussed her library's student social media takeover. Recognizing that the library's target audience is the student body and that librarians use social media very differently than students, student employees now manage the social media accounts for Giovale Library. Despite early staff concerns about everything that could go wrong, the students at Westminster have proven to be wonderful representatives of the library.

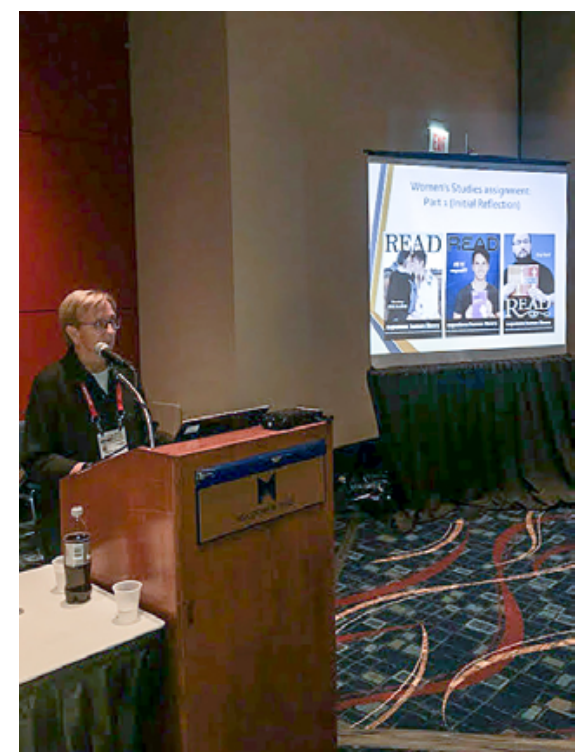

"The Human Library" presenter Yvonne Becker.

Sarah Sagmoen (director of learning commons and user services at University of Illinois-Springfield) discussed Brookens Library's student employee program, which sees students as stakeholders in the library rather than simply workers earning a paycheck. Students get opportunities for advancement by demonstrating teamwork skills, managing a broad range of tasks and increased responsibilities.

Ashley Todd-Diaz (head of special collections and university archives at Towson University) discussed her time at Emporia State University Library's Special Collections and Archives collecting undergraduate student experience artifacts. Special Collections and Archives worked with the Association of Student Government to establish the Leave Your Legacy program that encourages students to donate their personal papers.

Carissa Tomlinson (assistant university librarian for access and outreach services at Towson University) discussed Albert S. Cook Library's Leadership Institute, which emphasizes student leadership by encouraging student employees to develop, plan, implement, and ultimately be held accountable for their

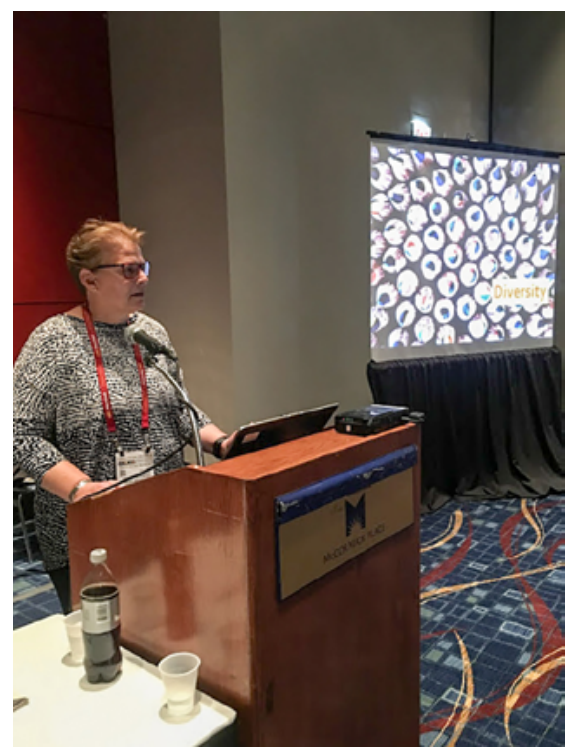

"The Human Library" presenter Nancy Goebel.

own programs.-Sean Hogan, University of Baltimore, shogan@ubalt.edu

\section{Using a human library to create diversity conversations}

Sponsored by ACRL and presented by Nancy Goebel and Yvonne Becker (both from the University of Alberta-Augustana), "The Human Library: Contributing to Campus Diversity" session described the concept of using a human library on a university campus to enhance empathy, diversity, and understanding among students, staff, and community members. After an initial survey of the attendees by the speakers regarding their fa- 
miliarity with the concept and organization of a human library, an informative summary on what a human library is was provided.

Included was information that defined what human books and readers are, the breadth of human book topics, and some important how-to tips. Strategies used to incorporate information literacy instruction by providing guidelines for citing human books, creating informal connections between human book topics and course material and assignments, and by encouraging further reading on human book topics, were presented.

Integrating the human library with the curriculum was described through an example of an innovative undergraduate Women's Studies assignment on sex, gender, and sexuality. This assignment gave the students opportunities to "read" human books, complete an annotated bibliography on the book topic, and reflect on the two ways of collecting information: narrative and scholarly methods.

To answer the question "Why offer a human library?" examples of responses to an assessment project showed that readers found value because, "You get to hear from first-hand experience in a personal setting," "It is an interactive learning experience," and "It helps me understand the lives of others."

Also, a human book responded that "Telling stories educates . . . the best way to reduce discrimination is to get to know someone different than you."

The lively Q\&A that followed provided the attendees with practical information on the organization of a human library considering the experiences of 17 Augustana human library events._Nancy Goebel, nancy.goebel@ ualberta.ca, and Yvonne Becker, ybecker@ ualberta.ca, University of Alberta-Augustana

\section{From MLS to MLD}

The ACRL Library Education Interest Group sponsored a program focused on the need for design thinking to be taught in LIS education. Steven Bell (Temple University) began by reminding the audience of his 2014 article in Library Journal, which proposed that librarianship is about designing servic- es rather than information science. A video provided the audience with a glimpse into how design thinking works in practice.

Rachel Clarke (professor at Syracuse University) contrasted design thinking with science and humanities disciplines. Design creates what should exist in the world to solve a problem. Her position is that librarianship has always implicitly created services that solve problems. The mindset now should explicitly draw on design tools and theories to support such activity.

Michelle Frisque (chief of technology, content and innovation at Chicago Public Library [CPL]) showed many concrete examples of redesigning services. Design begins with empathizing and connecting with users to understand their motivations and behaviors. Then, the design team tests a solution to the identified problem while being prepared to fail and try something different. Not everything works. She also told the audience about a publicly available toolkit designed by CPL with Aarhus Public Library.

Lynne Howarth (University of Toronto faculty member) represented LIS education discussing work on designing curriculum with a focus on innovation, change, and preparation for students to lead. She and two colleagues have written an article in a 2016 issue of JELIS (reprinted with permission at http:// slis.simmons.edu/blogs/ourinformationfuture /jelis-paper) and created a website (http://infofuture.simmons.edu) to document their project.

Reactors were Kate Marek (iSchool at Dominican University), Cinthya Ippoliti (Oklahoma State University), and Greg Diaz (CPL). They, and an audience of 50, made comments that lent support to the ideas in the presentation.-Nora J. Bird, University North Carolina-Greensboro, njbird@uncg.edu

\section{To teach or not to teach discovery tools}

Cosponsored by the ACRL Community and Junior College Library, Distance Learning, and Instruction Sections, "To Teach or Not to Teach Discovery Tools: Balancing Practical Instruction and the ACRL Information 
Literacy Framework" was a panel discussion that examined the challenges of and best practices for information literacy instruction using discovery services in four- and twoyear academic library settings, and in both face-to-face and distance learning formats.

Joe Brewer (Pima Community College) shared how he uses discovery tools in his lower-level undergraduate instruction to encourage topic development and exploration through the creation of "mind maps." Sarah end" of the discovery tools can help instruction staff share in the implementation and management of the tools, and can make the tools more effective for users.

The Q\&A session focused on techniques for teaching using the ACRL Framework for Information Literacy as a theoretical foundation, using limits, etc. to modify searches, and other topics.-David Oberhelman, Oklaboma State University, d.oberhelman@ okstate.edu

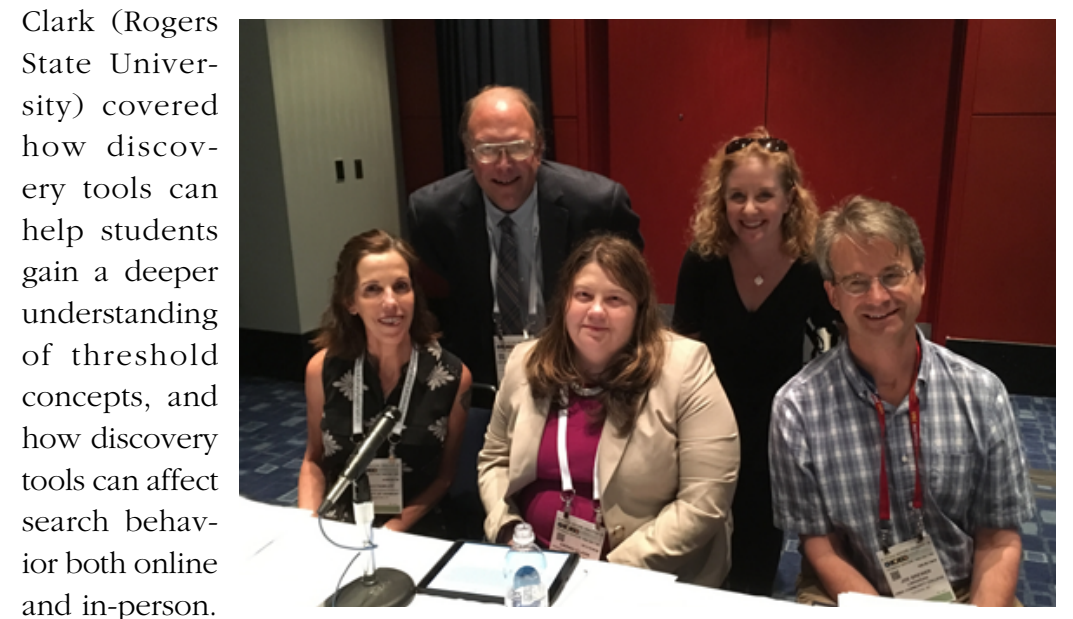

Ellysa Stern Cahoy (Pennsylvania State University LiPresenters for the discussion "To Teach or Not to Teach Discovery Tools" (left to right) (top row): David Oberhelman (moderator) and Ellysa Stern Cahoy (bottom row): Nancy Fawley, Sarah Clark, and Joe Brewer.

\section{Emotional Intelligence for professional success}

Many librarians of color face institutional and societal discrimination in varying degrees, including situations that lead to emotional responsestheirs or others'. During the ACRL Dr. E. J. Josey Spectrum Scholars Mentor Committee program "What They Don't Teach You in Library School: Using Emotional Intelligence to Succeed as Academic Librarians of Color," Leo Lo (Old Dominion University) and Kiyomi Deards (University of Nebraska-Lincoln) offered a number of strategies to manage situations and plan for long-term success.

Connect with peers. Lo noted that "Emotional Intelligence is the ability to make emotions work for you instead of against you." Deards suggested that awareness of self, work culture, and geographic microcultures are all elements that can help prepare a person in advance of an awkward interaction. She recalled a past co-worker counseling her, "Don't be offended if a person says, 'What 
are you?'” In the face of these interactions, Deards suggested listen, observe, strategize, respond as a communication approach that can de-escalate emotional situations.

Plan your career. "[S]uccessful people often have a vision for where they want to go, even when they are lost," Lo offered. A deeper sense of purpose behind one's work can be a crucial element for persevering. Additionally "career capital," including rare/ valuable skills and specializing in more than one thing, helps a person be adept and transferrable.

succeed at your job. Finally, SMART goals (specific, measurable, attainable, relevant, timebased) for the near future, and creating habits, small and ridiculously easy at first, are two useful strategies, but also be "award and promotion ready" by documenting achievements and notes for improvement,

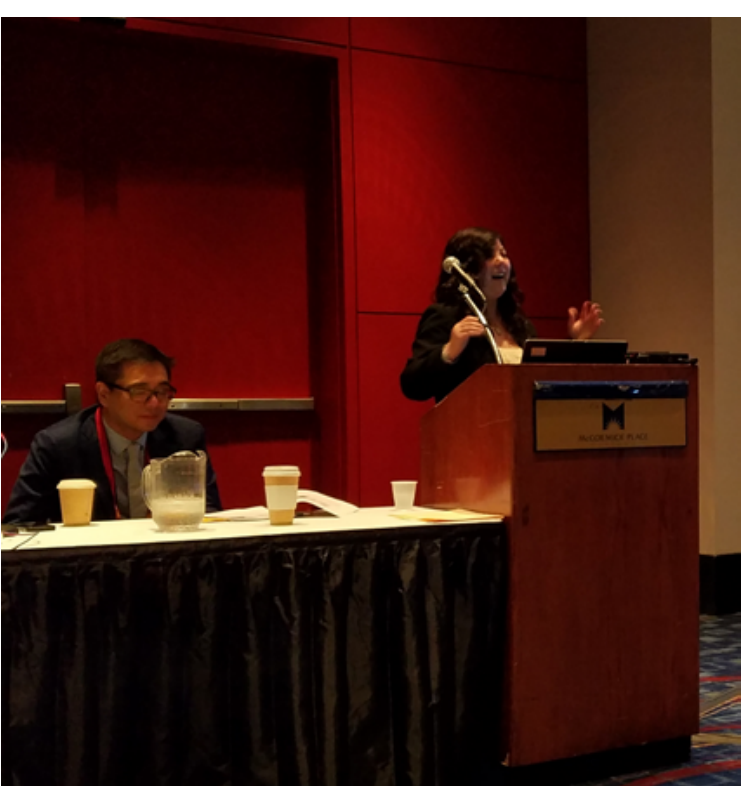

"What They Don't Teach You in Library School" presenters Kiyomi Deards and Leo Lo. finding sponsors,

and considering professional self-presentation.

The presentation resources website can be found at https://www.leoslo.com/resourcesala2017-eq/.-Heather James, Marquette University, heather.james@marquette.edu

\section{Transforming our academic outreach practices}

The panel session "Transforming Our Academic Outreach Practices: Reaching Our Students, Faculty and Staff, and Administrators," sponsored by the Library Marketing and Outreach Interest Group, was an informative discussion that included the perspectives and experiences of librarians from varying sizes of academic libraries.

Jason Kruse (Northwestern University) spoke about the connections he has forged on his campus in "Marketing the Library Through Campus Partners." Each partnership has been selected and maintained to benefit the library as well as the campus partner. Kruse gave practical advice about how to approach departments and begin to discover ways to work together.

Stephanie Espinoza's (College of Southern Nevada) presentation, "Marketing From the Heart," turned the focus to creating a student-centered library. Espinoza creates engaging events and interactive displays to encourage students to feel at home in the library. Most of the events and displays that Espinoza discussed were low-cost and easy to scale up or down, depending on library-size. For example, a "six word story contest" invites students to submit stories online or in person that tell the most complete and compelling story with just six words.

The last presentation was by Megan MacGregor (Penn State Wilkes-Barre). Her presentation, titled "Just Smile: A soft rebranding" offered useful advice for librarians on how to give the best customer service experience. By focusing on two key points, MacGregor was able to train library staff to support students and make them feel comfortable in the library. The rebranding process prioritized two concepts, "Be friendly," and 
"Be helpful." New programs like an undergraduate research day and a student advisory board supported the vision that MacGregor created.

Audience members contributed to the discussion with comments and questions about buy-in from administration, communication of services to colleagues, and training for student workers.-Amy Wainwright, John Carroll University, awainwright@jcu.edu

\section{Perspectives on data publishing}

Publishing data. Standards for data. Peer review of data. Processing repository data. "Perspectives on Data Publishing: Opportunities and Challenges," sponsored by ACRL's Publications Coordinating Committee and Research and Scholarly Environment Committee, tackled these issues.

Data publishing in libraries implicates libraries as partners in producing and supporting digital scholarship, and how they contribute to and support openness, argued Mark Newton (director of digital scholarship at Columbia University Libraries). Journals publishing data should establish data policies. Examples include: Journal of Librarianship and Scholarly Communications and Tremor and Hyperkinetic Movements Journal.

Wendi Arant Kaspar (professor at Texas A\&M University and editor of College $\varepsilon$ Research Libraries), offered an editor's view on data publishing, which College $\&$ Research Libraries is exploring. Journals have a responsibility to model quality and evolve alongside scholarly research. Moreover, peer review of data allows reviewers to pinpoint bias and evaluate authors' findings, but finding reviewers is a challenge. Journal of Peace Research is an exemplary model.

Next, Jared Lyle (director of data curation services for Inter-university Consortium for Political and Social Research [ICPSR)]), which curates and makes available data, presented ICPSR's model. He discussed data curation and clean-up. One issue
ICPSR faces is granting researchers access to disclosive data. They are considering credentialing, where once researchers are credentialed in responsible uses of disclosive data, they would not need to go a lengthy application process to access such data.

Finally, Heidi Imker (director of research data services at the University of Illinois at Urbana-Champaign Library) discussed their approach at the Illinois Data Bank. She highlighted policy and technical issues, such as the 2 terabytes per year data deposit allotment for faculty, assigning DOIs, and ingesting data using code. Challenges include the lack of domain expertise for review and curation, and data published in isolation from similar data or accompanying articles.-Emily Ford, Portland State University, forder@pdx.edu

\section{The best tool is you: Preservation and protest}

The message at the "Protest and Preservation" program was that libraries and librarians play an essential role in the preservation of nontextual knowledge, helping to create spaces beyond text and humanize important stories. The program, sponsored by the Politics, Policy, and International Relations Section and the Anthropology and Sociology Section with the ALA Gay, Lesbian, Bisexual, and Transgender Round Table, explored the preservation of knowledge generated through social activism by focusing on the specific works of the panelists: Richard GilmanOpalsky's research on social movements and the public sphere, Robert Camina's documentaries, Upstairs Inferno and Raid of the Rainbow Lounge, and Sonia Yaco's work on the Desegregation of Virginia Education (DOVE) project.

Opalsky discussed the importance of revolt in society and encouraged libraries to open their doors to provide people the spaces for activism. He challenged the traditional commitment to paper and discussed the importance of preserving and making accessible the non-textual elements of uprisings: oral 
histories, accounts, photos, and social media.

Filmmaker Camina demonstrated how he is bringing text to life through emotional clips of his award-winning documentary films, which focus on significant events in the LGBT community. In his remarks, Camina emphasized how stories can become more relatable when text is humanized through voices and images. He also reminded everyone in the audience that anyone with a smartphone capable of recording sound and images were documentarians themselves.

Yaco spoke about her work on the DOVE project, which seeks to create a new history and new understanding through oral histories, records, dialogue, and community building. As a librarian, she acknowledged the challenges faced by the profession in preserving the nontextual knowledge important to social justice and activism. In her discussion about finding the right tool, Yaco pointed out that in most cases, "The best tool is you." For further information on the panelists, the program, and social activism and preservation, visit the pathfinder at http://libguides.naz.edu/ protest.-Katie Elson Anderson, Rutgers University, katie.anderson@camden.rutgers. edu

\section{Giving voice to diverse collections through digitization}

The Rare Books and Manuscripts Section's panel "Giving Voice to Diverse Collections Through Digitization" focused broadly on the theme of how digitization and digital humanities projects can serve collections created by non-Anglo groups. Sarah Carlson presented on the University of Minnesota's Umbra Search; Mike Kelly discussed the acquisition and digitization of Native American materials at Amherst College; Alex Merrill presented on Mukurtu, an open source content management system; and Brenda Sendejo discussed Southwestern University's Latina History Project.

Each presentation highlighted different aspects of this complex issue. Carlson noted that Umbra Search effectively dispels the first barrier of discovery because it serves as a central hub for African American resources, eliminating the need to use an "African American" keyword search. Kelly highlighted the importance of respecting the knowledge indigenous peoples want to share with the world versus what should remain secret, and Amherst does not pursue any unique or private material in order to honor these restrictions. The Mukurtu project also aims to give indigenous people control over their materials by allowing tribal representatives to select the content they want included in the system and determining if any material should be restricted.

Finally, Sendejo pointed out how valuable students were to the Latina History Project. Working on the project gave them the opportunity to unbox and recover their own histories, and also provided a model to share with other students who might feel out of place at predominantly white institutions.

Common themes in the presentations were the importance of upfront manual labor to large digitization projects, the importance of allyship between project leaders and indigenous groups, and how metadata can inadvertently obscure relevant aspects of a work. Hopefully these and other projects will show ways in which we can diversify the archival record and bring previously overlooked resources to light._Elisabeth Brander, Washington University School of Medicine in St. Louis, ebrander@wustl.edu

\section{OERs}

More than 100 librarians attended the Science and Technology Section program "OERs: Strengthening the Academy with Open Resources." The panel was moderated by Sarah Crissinger (former leader of the OER Initiative at Davidson College).

The first speaker, Merinda McLure (health and human sciences librarian, University of Colorado-Boulder) discussed her previous work at Colorado State University 
(CSU), where she led the libraries' OER efforts from 2015 to 2017. McLure highlighted CSU's stipend program, in which faculty received $\$ 250$ stipends to attend OER workshops and review textbooks in their disciplines. In addition to leading workshops, librarians also facilitated opportunities for faculty to share their experiences with one another.

Nina Exner (researcher and grant support services librarian, North Carolina Agricultural and Technical State College) offered the unique perspective of a librarian who trains faculty to create OERs to fulfill science education grants. Exner also assists faculty in developing broader impacts sections of grant proposals. She stressed the importance of using "grant jargon" (not library jargon) when communicating with faculty and campus research offices.

The final speaker was Regina Gong (manager of technical services and systems, Lansing Community College), who collaborated with "faculty champions" to form a campus OER initiative in 2015. With administrative support, but no funding, Gong and her colleagues built a program that has impacted more than 10,000 students, saved more than $\$ 1$ million in textbook costs, and inspired faculty to create their own OERs. She emphasized that creative, persistent faculty outreach is critical to building and sustaining OER programs.

Although the OER initiatives represented in the program were markedly different from one another, all presenters identified collaboration within and across institutional boundaries as the ultimate key to success. More information about the panelists and resources mentioned in the program is available on the ACRL-STS Conference Program Libguide at http://acrl.libguides.com /STSALA2017.-Patricia Hartman, Auburn University, pjh0011@auburn.edu

\section{Feminist bookstores, past and present}

The Women and Gender Studies Section's Program "Women and Women First:
Feminist Bookstores, Past and Present" celebrated the history and current existence of feminist bookstores. Four panelists discussed the founding and running of feminist bookstores in a variety of circumstances.

Speakers included Sandra Torkildson (owner of A Room of One's Own Bookstore in Madison, Wisconsin), Lou Kaly (collective member of Bluestockings Bookstore in New York City), Ann Cristophersen (cofounder and co-owner of Women and Children First in Chicago), and Lynn Mooney (co-owner of Women and Children First).

Torkildson began by describing what led to the formation of A Room of One's Own Bookstore-simply, she and her peers wanted a place for women to gather that wasn't a bar. The bookstore was founded with \$5,000 and "nothing to lose." Another goal was to create a store that introduced women to feminist publishers and small presses. The two principles behind the running of the bookstore were to create a space for women and to pay women well for their work.

Christophersen discussed qualities that made Women and Children First in Chicago a cornerstone of the community. The store opened in 1979 and has survived ever since. While the bookstore was committed to serving as a gathering space for women, it was also fundamentally committed to being a feminist bookstore that sold books from feminist presses.

Mooney continued the story of Women and Children First and emphasized her desire for Chicago's young women writers to think of it as their bookstore.

Kaly discussed a very different model of running a bookstore: as a collective, staffed mainly by volunteers.

A lively Q\&A highlighted ways in which feminist (and independent) bookstores are increasingly run as nonprofits as well as similarities and differences among feminist bookstores._Nina Clements, California State University-Channel Islands, ninaclements@gmail.com $\rightleftharpoons 2$ 